www.jmscr.igmpublication.org

Impact Factor 5.84

Index Copernicus Value: 71.58

ISSN (e)-2347-176x ISSN (p) 2455-0450

crossref DOI:_https://dx.doi.org/10.18535/jmscr/v6i1.174

Journal Of Medical Science And Clinical Research

$\underline{\text { Research Article }}$

\title{
A Study to Assess the Knowledge Regarding Perineal Care among the Post Natal Mothers in Selected Hospitals of Pune City
}

\author{
Authors \\ Mrs. Manisha Gadade, Mr. Dere Sujit, Ms. Merlin Philip, Mrs. Jadhav Priyanka, \\ Ms. Aishwarya Chavan \\ Bharati Vidyapeeth Deemed to be University College of Nursing, Pune-43
}

\begin{abstract}
A study titled " $A$ study to assess the knowledge regarding Perineal care among postnatal mothers in selected Hospitals of Pune City" was conducted for the partial fulfillment of the Bachelor degree of nursing, Bharati Vidyapeeth Deemed University, Pune during the year 2017-2018.

Postnatal care which also includes Perineal care is one of the most important maternal health-care services for not only prevention of impairment and disabilities but also in reduction of maternal mortality. Safe motherhood report also highlights that the majority of women in developing countries receive almost no postpartum care.

The objective of the study was:

1. To assess the knowledge regarding Perineal care among postnatal mothers.

A non experimental research design was adopted to conduct the study. A total of 100 samples was selected by using non probability purposive sampling technique was adopted to select the ward and mothers meeting the inclusion criteria. Study instrument was self structured questionnaire used by the researcher which consists of two parts:

Part 1: Demographic Data

Part 2: Self structured questionnaire

The findings of the study revealed that $4 \%$ of postnatal mothers have poor knowledge regarding Perineal care, $76 \%$ of postnatal mothers have average knowledge regarding Perineal care and $20 \%$ of postnatal mothers have good knowledge regarding Perineal care. Overall result shows that postnatal mothers are having average knowledge regarding Perineal hygiene.
\end{abstract}

\section{Introduction}

Perineal care is often referred to as "Peri care." Perineal care involves cleaning the external genitalia and surrounding area. The Perineal area is conducive to the growth of pathogenic organism because it is moist and is not well ventilated. Since there are many orifices (urinary meatus, vaginal orifice and the anus) situated in this area, so the pathogenic organism can enter i Postnatal period is a crucial period in the life of women. They require special care during pregnancy, delivery and after delivery in order for safe motherhood and healthy living. Discomforts of postnatal period with episiotomy mothers will 
have physical and emotional discomfort. Many mothers are uneducated and ignorant about health practices. So the focus of nursing is to teach self care to maintain good health after delivery. ${ }^{9}$

Lack of Perineal care may lead to some other complication like puerperal pyrexia; Perineal infection by hemolytic streptococci and other infections affect the genital tract. Perineal care is important to prevent complication in that region the body .In order to prevent infection and bad There is a great role for mothers to participate in all these effects. Peoples involvement is essential, for it is an awareness leading to action. But this awareness and involvement can only come through self care. Health education programme is to be given in the hospital during the antenatal visit and people gain knowledge through television, radio, magazine, newspapers etc. So education is an essential need to the mother and community in order to gain adequate knowledge for maintaining positive health of herself and her baby .

Health education is an integral part of maternal and child health nursing care. During pregnancy and postnatal period nurses educate mothers about health behavior that enhance positive maternal infant outcomes. Particularly those related to self care.

We the researchers felt that educating mothers help to improve knowledge and practice of the Perineal care. ${ }^{15}$

\section{Need of the Study}

Mother's physical and psychological health will be impaired during postnatal period by Perineal trauma sustained during child birth. Perineum should be kept clean and free form dried blood. Perineal care help to prevent infection promote healing and provide comfort to the mother. Proper Perineal care is important in preventing infection of the episiotomy wound, bladder and uterus.

The main goal in Perineal care is to support the women recovery to pregnant state and educate the women about the Perineal care .The postnatal mothers should know how to do the Perineal care and its importance.

In India postnatal infection is the third cause of maternal death. It is mainly due to lack of Perineal care, breast care, and poor intake of food. Postnatal health practices such as hygiene, breast care Perineal care, postnatal diet, postnatal exercise and family planning will promote health and reduce the mortality and morbidity rate.

WHO (1990) The expert committee estimate on material health and safe motherhood programmer the major causes of material deaths were due to puerperal sepsis which account for $15 \%$ of all material deaths in developing countries If it does not cause death, puerperal sepsis can cause long term health problem such as chronic pelvic inflammatory disease and infertility. ${ }^{6}$

Practicing Perineal care during their postnatal period in hospital will enhance the mother selfesteem, skill knowledge, ability and confidence in performing self Perineal care at home.

\section{Research Statement}

"A study to assess the knowledge regarding Perineal care among the post natal mothers in selected in selected hospitals of Pune city."

\section{Objective of this Study}

To assess the knowledge regarding Perineal care among the post natal mothers.

\section{Methodology}

Descriptive research was used to assess the level of knowledge regarding perineal care among post natal mothers in the selected hospitals of pune city. The target population who fulfills the inclusion criteria are selected for this study, a nonprobability convenient Sampling Technique was used to select 100 samples. A 19 Self-Structured Questionnaires were formulated to assess the Level of Knowledge. Each corrected answer was given a score of one and wrong answer zero score. The score between poor 1-6, Average 7-13, Good 14-19. The tool was validated by 5 experts in department of Obstetrics and Gynecology faculty. 
Valuable suggestions were incorporated and tool was finalized. Permission was obtained from undergraduate research monitoring committee and institute ethical committee.

The reliability of tool was established by conducting a pilot study. The data collection was conducted for one month in selected hospital of Pune city. The investigator first introduced themselves to the postnatal mothers and developed a good rapport with them. The investigators explained the purpose of the study and then gained their confidence by obtaining a written consent from samples. The data collection was done by questionnaire method a separate questionnaire was used for each mother. Approximately 20 minutes were spent for each sample. Similarly the same data procedure was followed for the entire 100 samples.

\section{Major Study Findings}

Table 1 Frequency and percentage distribution according to knowledge of mother

\begin{tabular}{|l|c|c|c|}
\hline Sr. no. & Knowledge of mothers & frequency & Percentage \\
\hline 1 & Good knowledge & 20 & $20 \%$ \\
\hline 2 & Average knowledge & 76 & $76 \%$ \\
\hline 3 & Poor knowledge & 4 & $4 \%$ \\
\hline
\end{tabular}

$\mathbf{n}=\mathbf{1 0 0}$

\section{Pie diagram showing distribution of the sample in relation to knowledge regarding perineal care.}

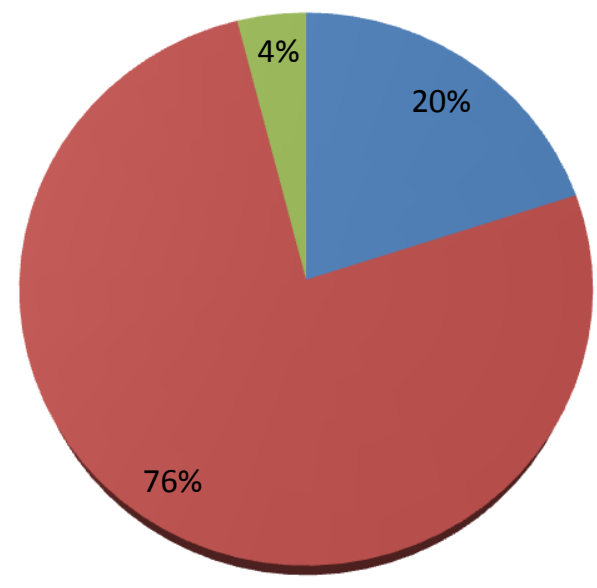

GOOD KNOWLEDGE

- AVERAGE KNOWLEDGE

POOR KNOWLEDGE

Figure (1) Pie diagram showing overall knowledge score regarding knowledge level of adolescent

Table No. 1 and figure no. 3 depicts the following 1.Showing that $76 \%$ postnatal mother have average knowledge regarding perineal care.

2. Showing that $4 \%$ of postnatal mothers have poor knowledge regarding perineal care.

3. Showing that $20 \%$ of postnatal mothers have good knowledge regarding perineal care .

\section{Implication}

The present study can help nurses to enrich the awareness through outreach programme regarding perineal care among postnatal mother. Basic nursing education should give importance to the hygiene, episiotomy care early detection of complication of post natal period and to remove the fallacy on perineal care. The findings of the study help the gynecology and obstetric nurses and students to develop the inquiry baseline. The general aspect of the study result can be made by further researcher to identify the level of fallacy regarding perineal care among postnatal mothers. 


\section{Conclusion}

After the detailed analysis this study leads to the following conclusion that the overall knowledge of the postnatal mothers of $76 \%$ of the mothers have an average knowledge regarding Perineal care and $20 \%$ of the mothers have a good knowledge regarding Perineal care.

Thus the study findings clearly reveal that the knowledge of mothers regarding perineal care is average need to create the awareness and instill a positive approach regarding Perineal care.

\section{Acknowledgement}

These efforts in my academic endeavor would not have been a reality but for the constructive and purposeful support, guidance and encouragement rendered by a number of a person, whose help we especially recognize through this acknowledgement.

Firstly, we are grateful to almighty God and our Parents whose grace, unconditional love and blessing we accompanied throughout the study. Our sincere and whole hearted thanks to Mrs. Pravina Mahadalkar, Incharge Principal, and head of Department of Obstetrics and Gynaecology Nursing), Bharati Vidyapeeth University, College of Nursing, Pune for extending her support and granting permission to conduct the study with necessary administrative permission.

We express our profound gratitude to our guide Mrs. Manisha Gadade Clinical Instructor and also Mrs. Sushila Thockchom, Fourth year B.Sc. Nursing Coordinator for constant support and guidance., Bharati Vidyapeeth University College of Nursing, who through their constant encouragement, valuable guidance and sustained patience made us to accomplish this study. The discipline and freedom she gave in our work, her affectionate words and good sense of humor kept us high moral and self-confident throughout the study. We pay our regards to her for giving the privilege of being her student Researcher. We demand on her valuable time and energy excessive, but she was always kind enough to be available for discussion and guidance. So, we would like to give sincere expression of gratitude and indebtedness is extended to her.

We are grateful to Mrs. Shanta De (H.O.D. of Medical- Surgical nursing), Mrs. Anita Sali (associate professor),Mrs. Supriya Pottal (Assistant professor) and Mrs. Rajee Sebin (Tutor) of Bharati Vidyapeeth College of Nursing ,Pune for helping and guiding us and supporting us throughout the period of study. We express our sincere gratitude to all faculty members and administrative staff of the College of nursing their support, encouragement and valuable suggestion, throughout the period of study.

We especially thank all the participants for this study without their cooperation it would have been impossible to conduct the study. We would like to thank all the experts in the field of Obstetrics and Gynaecology Nursing for their valuable suggestion and validation of the data collection instrument. We are grateful to Mrs. Vijaya Chalukya and statistician for her valuable guidance in statistical analysis.

We extend my sincere thanks to all my friends, colleagues and well wishers for their good wishes in for this study. We are totally indebt to our family and our friends for the constant encouragement, patience and support throughout the study, without which this dream of doing the study could never have been realized.

We owe all our efforts and success to Almighty God for this abiding grace and mercy which has made this study possible!

\section{Ethical Clearance}

- Administrative approval from college ethical committee.

- Permission taken from authority of selected Hospitals in Pune city.

- The whole process is described to the participants.

- Informed written consents were taken from the participants.

- Demographic data was collected. 
- Structured questionnaire was given to the participants and they were given 20 minutes to solve the questionnaire.

\section{References}

1. D.C.Dutta (2004) Textbook of Obstetric including perinatology and contraception, $\left(16^{\text {th }}\right.$ ed) new central book agency (p)Ltd., chintamoni Das lane, Pg.no. 153.

2. Sweet. R.L and Ledger W.(1973) Peripheral infections Morbidity, American Journal of obstetrics and Gynaecology, Pg no. 18-20.

3. Walfisch. A. Hallak M.(2002) Episiotomy and perineal care a review of literature journals of obstetrics and Gynaecology, Pg no. $60-61$

4. Grundy1 (1997) role of the Midwife in perineal wound care following childbirth.

5. Cunningham, et,al(2001) Williams obstetrics $\left(20^{\text {th }}\right.$ ed)Stamford, Appleton and Lange. Pg no86.

6. Basvanthappa B.T Textbook of midwifery and reproductive health nursing. New Delhi: J.P Publications ; 2005 pg no; 87-98

7. Dr. Sharma $S$ Nursing research and statistics $2^{\text {nd }}$ Edition, Pg no. 40,72,138,286,291.

8. Missiriya S. Knowledge and practice of postnatal mothers regarding personal hygiene and newborn care.International journal of Pharmaceutical science Review and Research. 2016 november 2,40(1) Pg no. 89-93. Available from : https://www.researchgate.net/publication/3 09609338

9. Purani $\mathrm{C}$,et al. knowledge awareness and practice of Postnatal care among mothers. Indian J Child Health. 2015;2(2): 83-85.

10. Timilsina S, Dhakal R. Knowledge on postnatal care among postnatal mothers. Saudi Journal of Medical and Pharmaceutical Sciences. 2015 Dec; 1(4). 87-92
Available

from:

http://scholarsmepub.com/sjmps/

11. Oxford dictionary and thesaurus, $21^{\text {st }}$ ed Oxford University press, 2010. Assess pg no. 40

12. Oxford dictionary and thesaurus, $21^{\text {st }}$ ed Oxford University press , 2010. Knowledge pgno.419

13. Polit D. Hungler .B. P Nursing Research, Principles, methods. Philadelphia: J.B Lippincot publishers; 1999.

14. Treece \& Treece. Elements of research in Nursing. Philadelphia : Mosby company ; 1986.

15. Barger M.K.(1990) perineal care journal of midwifery.

16. Cleary-Goldman J.Robinson, J.N. (2003) The role of Episiotomy in current obstetric practice.

17. Faruel Fosse-Fosse H. Vendittelli F (2006) can we Reduce the episiotomy rate Journal of Gynecol obstet Biol Reprot IS68-IS.

18. Spring House(1994) Nursing theories and models (12nd edition spring house corporation pennsy vanio)

19. Deenamma koshy. Efficiency of perineal care in postnatal mothers. www.google.com/selfperineal care in postnatal mothers;2017.

20. Tomey AM , Alligod MR. Nursing theorists and their work . $5^{\text {th }}$ edition. St. Louis Mosby ; 2002

21. Akash Kudale .et al. A study to assess the Knowledge of postnatal mothers regarding self care after child birth in Bharati Hospital and research centre ,Pune 201617.

22. Annamma Jacob. A comprehensive textbook of midwifery and Gynecological Nursing. $3^{\text {rd }}$ edition New Delhi. Jaypee Brothers Medical Publishers(P)Ltd : 2017.

23. Ali L. Assessment of mothers Knowledge regarding Postpartum self care in national Ribat University Hospital . 2015 
24. Rose M.N Foundation of Nursing research $3^{\text {rd }}$ edition . New Jersey; Berentice Hall.

25. Macmillan Dictionary [Internet ] Available from: http://www.google.com/amp/s/www.mami llandictionary.com/license/amp/dictionary/ british/

26. Elghany M.Minor discomfprt during postpartum period [Internet]. 2016 Nov 20 Available from: http:// medicallibarrary .blogspot.in/2016/il/minor- discomfort during postpartum.html.

27. Fox, David. The research process in nursing . $4^{\text {th }}$ edition New York : Appleton country crofts.1967 p 342-343.

28. Rajakumari.G et al . structured education knowledge on postnatal diet among postnatal mothers. International Journal of recent scientific research 2015, Magi, vol.6 Issue , 5: 3929-32 Available from: http://www.recentscientific.com

29. Essential Antenatal, perinatal and postpartum care- Training modules. Europe : WHO ;2002 Feb.

30. Diraian S. The meaning of postnatal mothers [Internet] 2015 Available from: https//www.livestrong.com/article/536702the meaning of postnatal mother. 